\title{
EFFECT OF DIFFERENT PRESENTATIONS OF RESVERATROL ON CELL PROLIFERATION AND EPITELIAL THICKNESS OF THE ORAL MUCOSA OF WISTAR RATS
}

\author{
Luciano Henrique Jesus ${ }^{1}$, Juliano Cavagni², Vinicius Coelho Carrard², \\ Cassiano Kuchenbecker Rösing², Manoel Sant'Ana Filho ${ }^{1,2}$
}

\begin{abstract}
Introduction: Grape is one of the most important fruit crops across the world and can be consumed in different ways. There has been a growing interest in the role of antioxidants such as resveratrol, which can be found in grape skin, in oral and dental tissues. Thus, the objective of this study was to analyze the effect of different presentations of resveratrol on cell proliferation and epithelial thickness of the oral mucosa of Wistar rats.
\end{abstract}

Methods: Fifty male Wistar rats were randomly divided into five groups: water/control, red wine, grape juice, $12 \%$ alcoholic solution/ethanol and aqueous solution of resveratrol. Samples of palatal and tongue mucosa were collected for a histomorphometric analysis using hematoxylin-eosin staining and the argyrophilic nucleolar organizer region (AgNOR) technique for quantification of cell proliferation.

Results: As to epithelial thickness, both the tongue and the palate showed a statistically significant difference between the control group and the other groups, with greater decrease in the resveratrol and the wine groups. In the suprabasal layer of both the tongue and the palate epithelium, red wine reduced the rate of cell proliferation, while ethanol increased it. In the basal layer of the tongue epithelium, there was a statistically significant difference between the control, the grape juice and the resveratrol groups and the ethanol group, with increased cell proliferation in the ethanol group.

Conclusions: Wine does not interfere in the physiological renewal of the basal layer of the buccal epithelium and exerts a protective action by reducing the cell proliferation rate of the suprabasal layer.

Keywords: Resveratrol; grape juice; wine; cell proliferation; epithelial thickness.

Grape is one of the most important fruit crops across the world and can be consumed in different ways. There are at least 36 phenolic compounds with antioxidant activity in grapes, and their benefits include elimination of free radicals, inhibition of lipid oxidation, reduction of hydroperoxide formation, reduction of plasma oxidative stress, and antiaging effect ${ }^{1,2}$.

The relationship between diet and health has prompted intense research into bioactive compounds in foods. Resveratrol is a bioactive compound that can be found in grape skin (e.g., grape juice, wine and compounding solution of resveratrol) and may have been partly responsible for the health-promoting properties observed in populations in the Mediterranean region ${ }^{3,4}$.

There has been a growing interest in the role of antioxidants, such as resveratrol, in oral and dental tissues. Recent studies have indicated the need for antioxidant supplements for the prevention and successful treatment of disorders associated with gingival tissues and other structures supporting the teeth ${ }^{5,6}$. Multiple reports on resveratrol have shown its potential benefits of preventing or neutralizing cell damage, aging, cancer and other diseases ${ }^{5,7}$. The beneficial effects attributed to this phenolic compound include antioxidant, antiangiogenic, anti-inflammatory, antiviral and antitumor
Clin Biomed Res. 2017;37(3):175-180

1 Graduate Program in Dentistry, Oral Pathology, Universidade Federal do Rio Grande do Sul (UFRGS). Porto Alegre, RS, Brazil.

2 School of Dentistry, Universidade Federal do Rio Grande do Sul (UFRGS). Porto Alegre, RS, Brazil.

Corresponding author: Luciano Henrique Jesus drlhjesus@gmail.com Graduate Program in Dentistry, Oral Pathology, Universidade Federal do Rio Grande do Sul (UFRGS)

Rua Ramiro Barcelos, 2492, $2^{\circ}$ andar. 90035-007, Porto Alegre, RS, Brazil. 
properties. In vitro, resveratrol induced the production of vascular endothelial growth factor and increased angiogenesis in human peripheral blood progenitor cells. Physiological concentrations of resveratrol may increase the survival of human $B$ cells and regulate bidirectionally the effect of cell proliferation and the cell cycle. The incorporation of resveratrol into the liposomes increased the rate of cell proliferation and survival under stress conditions caused by UV-B light. The multiplicity of biological effects of resveratrol is mainly caused by the amount and diversity of molecular targets of this compound, such as cyclooxygenase/lipo-oxygenases, a wide range of kinases, sirtuins, transcription factors, cytokines, DNA polymerase, adenylyl-cyclase, ribonucleotide reductase, aromatase, among others. Resveratrol is assumed to have a complex physiological action because of its ability to modulate the different pathways in a micromolar range 8,9 .

Many studies have shown that resveratrol has antiplatelet, antioxidant, anti-inflammatory and antitumor effects, provides cardiovascular protection and reduces blood glucose ${ }^{9,10}$. By increasing the production of nitric oxide, resveratrol inhibits platelet aggregation and stimulates vasodilation.

Although it is known that resveratrol has antioxidant and anti-inflammatory properties, the effects of resveratrol on the oral mucosa have not been evaluated yet. Thus, the objective of this study was to analyze the effect of different presentations of resveratrol on cell proliferation and epithelial thickness of the oral mucosa of Wistar rats ${ }^{11,12}$.

\section{METHODS}

\section{Ethical considerations}

The present study was approved by the Institutional Review Boards of both Universidade Federal do Rio Grande do Sul (protocol number 26632) and Hospital de Clínicas de Porto Alegre (project number 14/0335).

\section{Experimental procedures}

Fifty male Wistar rats (45 days of life) with approximately $300 \mathrm{~g}$ of body weight were randomly divided into five groups after stratification by weight as follows: water/control; red wine (Almaden ${ }^{\circledR}$ Cabernet Sauvignon, Bento Gonçalves, Brazil); grape juice (Sunny Days ${ }^{\circledR}$, Bento Gonçalves, Brazil); $12 \%$ alcoholic solution/ethanol (same concentration of red wine, Vetec $^{\circledR}$, Rio de Janeiro, Brazil); and aqueous solution of $0.06 \mathrm{~mL} / \mathrm{L}$ resveratrol (compounding pharmacy).

All animals were fed laboratory rat chow and received solutions according to each experimental group. Solution and food intake was spontaneous and ad libitum. The animals were housed in boxes of five animals each in a controlled environment (temperature of $22^{\circ} \mathrm{C} \pm 2{ }^{\circ} \mathrm{C}$ and a dark/light cycle of 12 hours) during the whole experimental period (10 weeks). They were decapitated after this period.

A fragment of oral mucosa from the palate and the tongue were then collected for a histomorphometric analysis. All specimens were fixed in $10 \%$ neutral buffered formalin for 24 hours, embedded in paraffin and transversely sectioned, so that all the epithelial and connective layers could be visualized. Two 4- $\mu \mathrm{m}$ sections were cut from each specimen: one was stained with hematoxylin-eosin, and the other one was silver stained for nucleolar organizer region (AgNOR) counting according to the method described by Ploton et al. ${ }^{13}$.

Images of microscopic fields of all slides were captured with a JVC video camera, model TK-C620 (Victor Co., Tokyo, Japan) connected to a Zeiss Standard 20 binocular microscope (incluir dados do fabricante) at $1,000 \times$ magnification. Olympus immersion oil (Olympus Optical Co. LTD., Tokyo, Japan) was also used.

Each slide was analyzed starting from the end where the specimen was cut. Images were recorded for 30 consecutive microscopic fields or for all microscopic fields when there were fewer than 30 .

The evaluation procedure consisted of the quantification of number and area of AgNOR dots per nucleus in the mucosa cells. One hundred cells were evaluated per slide: 50 basal layer cells and 50 suprabasal layer cells. As many fields as necessary were analyzed until the desired number of cells from each layer for each specimen was obtained. The ImageTool 3.0 software (University of Texas, San Antonio, USA) was used for the analysis, in accordance with the manufacturer's instructions. The dots were counted visually, and their areas were measured with the digital subtraction tool. The computer software was used for calculations. Cells with overlapping or folded nuclei and areas with artifacts were excluded from the analysis. Associated dots were counted as one dot, according to the method established by Crocker et al. ${ }^{14}$.

Measurement procedures were adjusted before quantification, and the same adjustments were performed again before the end of data collection. To measure agreement, one slide was randomly chosen, and 50 cells were counted using the same method at the beginning of the trial and 2 weeks later. Kappa coefficient was 0.7. An examiner blinded to which group the slides belonged performed the analyses.

Epithelial thickness was measured from the basal membrane to the granular layer and used to indicate proliferative activity in three microscopic fields per slide at $400 \times$ magnification. 
Means and standard deviations were evaluated through one-way analysis of variance (ANOVA) according to the distribution of the data. Data were considered normal except for the palate/AgNOR/basal layer group -Kruskal-Wallis test. The level of significance was set at $95 \%$.

\section{RESULTS}

The photomicrographic images are presented in Figure 1. They show cell proliferation in the palate epithelium of Wistar rats.

Epithelial thickness in both the tongue and the palate decreased in the wine group compared with the other groups $(p<0.05)$ (Figure 2A and B). As to cell proliferation, no difference was found between the groups $(p>0.05)$ in the basal layer of the palate epithelium, whereas in the basal layer of the tongue epithelium there was a decrease in the alcohol group $(p<0.05)$ (Figure 2C and D). In the suprabasal layer of both the palate and tongue epithelium, cell proliferation decreased in the wine group and increased in the alcohol group $(p<0.05)$. In the grape juice group, a decrease in the cell proliferation of the tongue epithelium was also observed $(p<0.05)$ (Figure 2E and F).

\section{DISCUSSION}

In this study, we evaluated the effects of different presentations of resveratrol on the oral mucosa of Wistar rats. In the suprabasal layer of both the tongue and the palate epithelium, red wine reduced the rate of cell proliferation, while ethanol increased it. This can be explained by the fact that wine is composed of a mixture of several compounds, the main ones being resveratrol (a phenolic compound), melatonin (an indolamine) and hydroxytyrosol (a phenyl ethyl alcohol). These three substances interfere in the cell cycle. Resveratrol inhibits the enzymatic activity of the two forms of cyclooxygenase, inducing cell cycle arrest and apoptosis ${ }^{15,16}$.
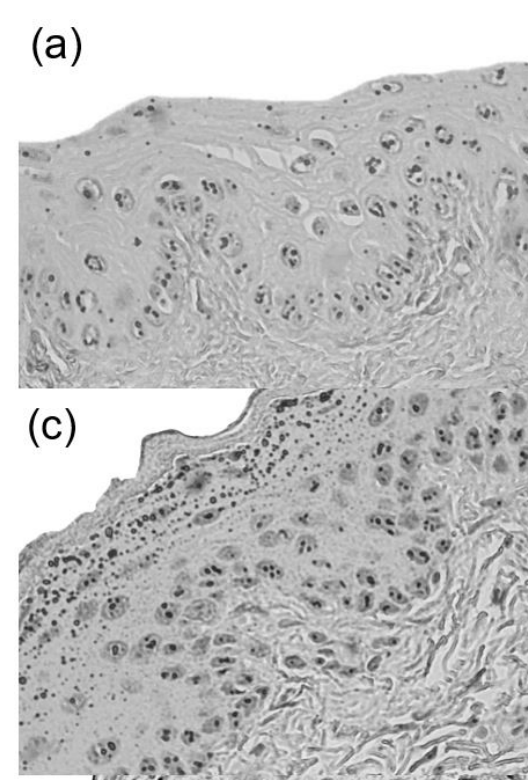

(b)

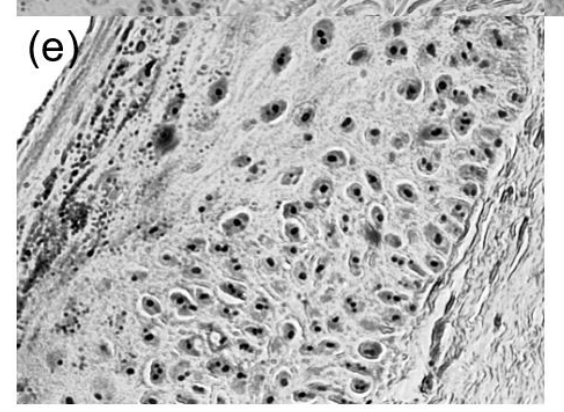

Figure 1: (a) Control; (b) Red wine; (c) Resveratrol; (d) Grape juice; (e) Ethanol. These photomicrographic images show the palate epithelium of Wistar rats at $400 \times$ magnification. The specimens were silver-stained for nucleolar organizer region (AgNOR) counting. AgNORs can be described as black dots found in the nuclei, and a large number of these dots can be seen in proliferating cells. Therefore, AgNOR is a marker that provides information on the rate of cell proliferation. This contrasts with most proliferation markers, which indicate only whether a cell is in division. 
A

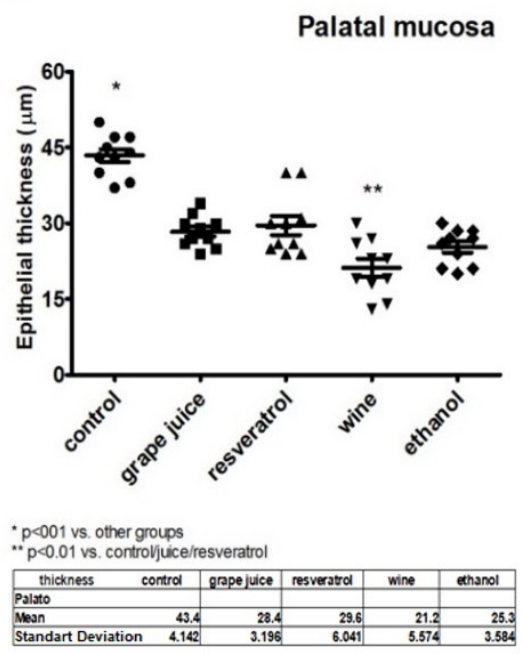

C

Basal layer cell - Palate

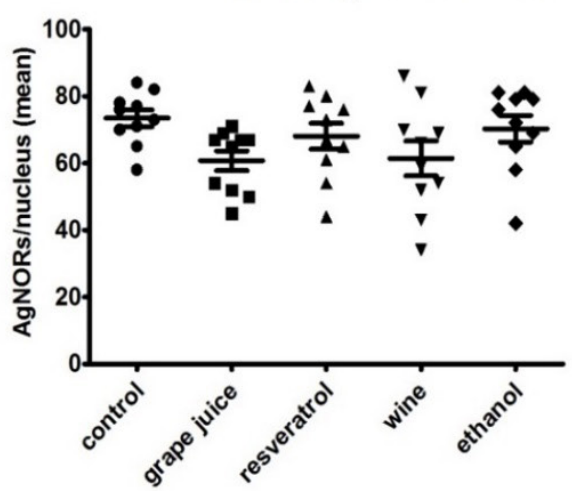

$p=0.08$ (Kruskat-Wallis)

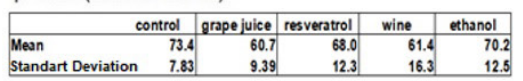

E

Suprabasal layer cell - Palate
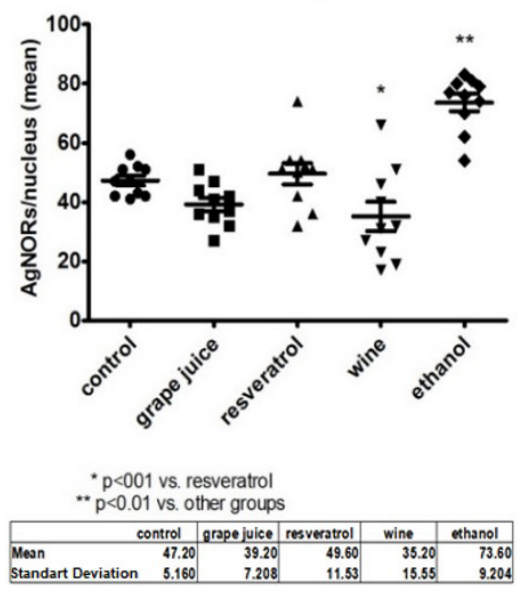

B

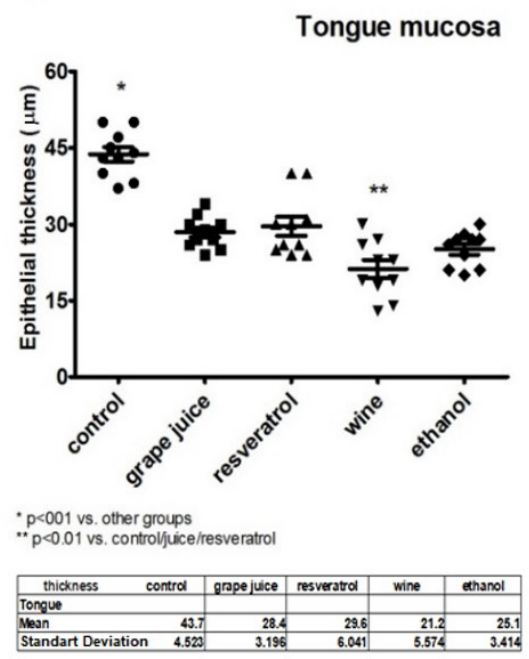

D

Basal layer cell - Tongue

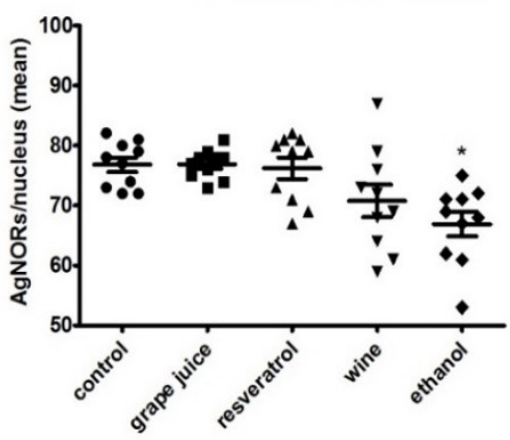

* p<001 vs. control/ grape juice / resveratrol

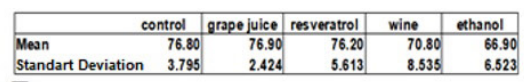

$\mathbf{F}$

Suprabasal layer cell - Tongue

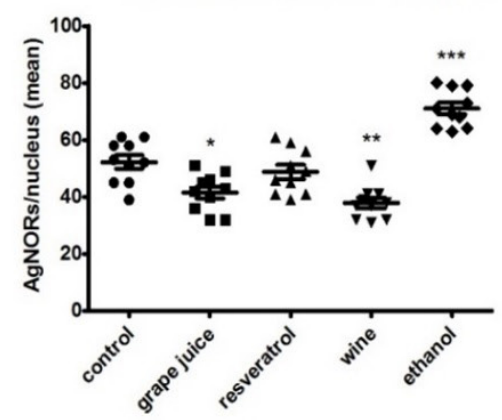

- $p<001$ vs. control

" $p<001$ vs. control / resveratrol

-." $p<0.01$ vs. other groups

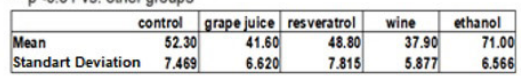

Figure 2: Statistical analysis of the groups in relation to epithelial thickness and cell proliferation (AgNOR counting). (A) Ephitelial thickness - Palatal mucosa; (B) Ephitelial thickness - Tongue mucosa; (C) AgNORs/Nucleus - Basal layer cell - palate; (D) AgNORs/Nucleus - Basal layer cell - tongue; (E) AgNORs/Nucleus - Suprabasal layer cell - palate; (F) AgNORs/Nucleus - Suprabasal layer cell - tongue. 
However, the results showed that resveratrol alone had no effect, suggesting that the association of the compounds is responsible for this interference in cell proliferation. This was corroborated by the results of the grape juice group, which showed reduced epithelial activity only in the suprabasal layer of the tongue. In the wine group, a reduction of the proliferative activity in the suprabasal layer of both the tongue and the palate was observed. These results are consistent with studies that indicated a difficulty in defining the dosage to be used of the isolated resveratrol to achieve the same effects ${ }^{15-17}$.

As for the cell proliferation in the palate epithelium, the basal layer showed no statistically significant difference between the groups, and this was probably due to the fact that proliferation physiologically occurs in this layer. In the tongue epithelium, a statistically significant difference was observed between the control, the grape juice and the resveratrol groups and the ethanol group, with increased cell proliferation in the ethanol group. As shown in the photomicrography, ethanol favored cell proliferation across all layers of the epithelium, whereas in the other groups the amount of AgNORs decreased and even disappeared in the upper layers. This is consistent with the results of the suprabasal layer of the palate epithelium, which showed a statistical difference between the ethanol group and the other groups, with increased proliferation in the ethanol group. In the suprabasal layer of the tongue epithelium, a statistical difference was observed between the grape juice group and the wine group, with reduced proliferation in the wine group, and between the resveratrol group and the ethanol group, with increased proliferation in the ethanol group. This difference in the effect of the groups between the tongue epithelium and the palate epithelium can be explained by the different shapes of the contact surface of these epithelia - the papillae of the tongue increases the contact surface. The reservoir of polyphenols also increases the effects ${ }^{5-7}$.

It is known that resveratrol is mostly found in grape skin, so its quantity and quality depend on two factors: cultivation (grape type, ripening, climate, soil, postharvest handling) and processing and manufacturing parameters. Winemaking has been described as a careful and elaborate process that has profound effects on the amount of resveratrol present in the final product ${ }^{9}, 10,12,18$.

Regarding the action of ethanol, studies conducted by our group have shown that the topical and intermittent exposure to alcohol causes an increase only in cellular desquamation, while the continuous ingestion of alcohol is associated with an increase in cellular proliferation. These findings have led to the conclusion that this increase is caused by the local or systemic effect of alcohol, observed only in cases of frequent and continuous use of alcohol. The results of these studies indicated that intermediate layer cells are responsible for increased cell proliferation, and no change was observed in basal layer cells in any group since these cells are constantly undergoing physiological division. Therefore, when there is a greater demand for cell replacement, intermediate layer cells, which normally do not proliferate very actively, show increased proliferative activity ${ }^{19-22}$.

\section{CONCLUSION}

According to the present study, wine does not interfere in the physiological renewal of the basal layer of the buccal epithelium and exerts a protective action by reducing the cell proliferation rate of the suprabasal layer.

\section{Acknowledgements}

This study was supported by the Coordenação de Aperfeiçoamento de Pessoal de Nível Superior, Brazil (CAPES - grant from PROCAD-NF 2008) and Incentive Fund for Research and Events of the Hospital de Clínicas de Porto Alegre, Brazil (FIPE - grant number 14-0335).

\section{Conflicts of interest}

The authors declare no conflicts of interest.

\section{REFERENCES}

1. Frémont L. Biological effects of resveratrol. Life Sci. 2000;66:66373.

2. González-Gallego J, GarcíaMediavilla MV, Sánchez-Campos S, Tuñón MJ. Fruit polyphenols, immunity and inflammation. $\mathrm{Br} \mathrm{J}$ Nutr. 2010;104:S15-27.
3. Kalantari H, Das DK. Physiological effects of resveratrol. Biofactors. 2010;36:401-6.

4. Szekeres T, Fritzer-Szekeres M, Saiko $P$, Jäger W. Resveratrol and resveratrol analogues--structureactivity relationship. Pharm Res. 2010;27:1042-8.
5. Araim O, Ballantyne J, Waterhouse $A L$, Sumpio BE. Inhibition of vascular smooth muscle cell proliferation with red wine and red wine polyphenols. $J$ Vasc Surg. 2002;35:1226-32.

6. Athar M, Back JH, Kopelovich L, Bickers DR, Kim AL. Multiple molecular targets of resveratrol: anti-carcinogenic mechanisms. Arch Biochem Biophys. 2009;486:95-102. 
7. Bianchini $F$, Vainio $H$. Wine and resveratrol: mechanisms of cancer prevention? Eur J Cancer Prev. 2003;12:417-25.

8. Chiva-Blanch G, Arranz S, LamuelaRaventos RM, Estruch R. Effects of wine, alcohol and polyphenols on cardiovascular disease risk factors: evidences from human studies. Alcohol Alcohol. 2013;48:270-7.

9. Opie LH, Lecour S. The red wine hypothesis: from concepts to protective signalling molecules. Eur Heart J. 2007;28:1683-93.

10. Diaz-Gerevini GT, Repossi G, Dain A, Tarres MC, Das UN, Eynard AR. Beneficial action of resveratrol: how and why? Nutrition. 2016;32:174-8.

11. Pirola L, Fröjdö S. Resveratrol: one molecule, many targets. IUBMB Life. 2008;60:323-32.

12. Varoni EM, Lodi G, Iriti M. Ethanol versus phytochemicals in wine: oral cancer risk in a light drinking perspective. Int J Mol Sci. 2015;16:17029-47.
13. Ploton D, Menager M, Jeannesson P, Himber G, Pigeon F, Adnet JJ. Improvement in the staining and in the visualization of the argyrophilic proteins of the nucleolar organizer region at the optical level. Histochem J. 1986;18:5-14.

14. Crocker J, Boldy DA, Egan MJ. How should we count AgNORs? Proposals for a standardized approach. J Pathol. 1989;158:185-8.

15. Kennedy JA, Matthews MA, Waterhouse AL. Changes in grape seed polyphenols during fruit ripening. Phytochemistry. 2000;55:77-85.

16. de la Lastra CA, Villegas I. Resveratrol as an anti-inflammatory and antiaging agent: mechanisms and clinical implications. Mol Nutr Food Res. 2005;49:405-30.

17. Lorimier AA. Alcohol, wine, and health. Am J Surg. 2000;180:357-61.

18. Vang O. Resveratrol: challenges in analyzing its biological effects. Ann N Y Acad Sci. 2015;1348:161-70.
19. Carrard VC, Pires AS, Mendez M, Mattos F, Moreira JC, Sant'Ana Filho M. Effects of acute alcohol consumption and vitamin E cotreatment on oxidative stress parameters in rats tongue. Food Chem Toxicol. 2009;47:1058-63.

20. Carrard VC, Filho MS, Rados PV, Chaves ACM, Lauxen I S. Quantification of silver-staining nucleolar organizer region in epithelial cells of tongue of mice after exposure to, or intake of, alcohol. Alcohol. 2004;34:233-8.

21. Carrard VC, Pires AS, Badauy CM, Rados PV, Lauxen IS, Sant'Ana Filho M. Effects of aging on mouse tongue epithelium focusing on cell proliferation rate and morphological aspects. Bull Tokyo Dent Coll. 2008;49:199-205.

22. Maito FLDM, Rados PV, Filho MS, Barbachan JJ, Quadros O. Proliferating cell nuclear antigen expression on tongue of mice after intake of, or topical exposure to, alcohol. Alcohol. 2003;31:25-30.

Recebido: Fev 16, 2017 Aceito: Ago 04, 2017 